\title{
COBALT ELECTRODEPOSITION ONTO STAINLESS STEEL 304 FROM AMMONIACAL SOLUTIONS
}

\author{
NANCY RAMOS-LORA ${ }^{1}$, L.H. MENDOZA-HUIZAR ${ }^{1, *}$ AND C.H. RIOS REYES ${ }^{1}$ \\ ${ }^{1}$ Universidad Autónoma del Estado de Hidalgo. Centro de Investigaciones Químicas, Mineral de la Reforma, Hidalgo. C.P. 42186, México.
}

(Received: September 29, 2009 - Accepted: April 26, 2011)

\begin{abstract}

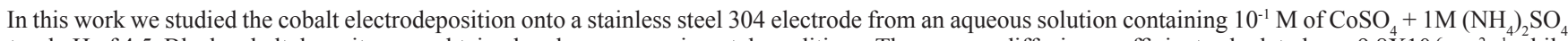
at natural $\mathrm{pH}$ of 4.5. Black cobalt deposits were obtained under our experimental conditions. The average diffusion coefficient calculated was $9.8 \mathrm{X} 10^{-6} \mathrm{~cm}^{2} \mathrm{~s}^{-1} \mathrm{while}^{4}$ the $\Delta G$ for the formation of stable nucleus was $1.013 \times 10^{-20} \mathrm{~J} /$ nuclei. The critical cluster's size calculated was 0 which suggested that each active site is a critical nucleus on the SSE-304 surface. The Scanning Electron Microscopy images showed the formation of non-uniform cobalt particles.
\end{abstract}

Keywords: Black cobalt, SSE 304, electrodeposition, kinetic.

\section{INTRODUCTION}

Often, a cobalt film is deposited onto a stainless steel electrode (SSE) to prevent its oxidation ${ }^{1}$. Several studies suggest that the cobalt films can be electrodeposited onto an SSE, if the deposition time and the cobalt concentration in solution can be controlled ${ }^{2,3,4}$. Thus, in such studies the thickness of the deposited film and the rate of mass deposition are the main parameters to analyze ${ }^{1,2,4-7}$. Cobalt electrodeposition onto SSE has been analyzed from sulfate and nitrate solutions ${ }^{3}$ while containing boric acid, ammonium citrate, tartaric acid and sodium chloride have been studied for cobalt plating baths ${ }^{4}$. Here, it is interesting to mention that the cobalt electrodeposition onto SSE from ammoniacal solutions has not been studied, in spite of the fact that it has been reported that the $\left(\mathrm{NH}_{4}\right)^{+}$ions in solution allow inducing the growth of smaller cobalt clusters and homogeneous deposits which might control the microstructure of the deposit ${ }^{8}$. Thus, even though the cobalt film deposited onto SSE has a great significance in the corrosion field ${ }^{1}$, the kinetic parameters related to this process are unclear yet. Only a work reports the nucleation parameters associated with cobalt electrodeposition onto SSE from nitrate solutions ${ }^{3}$. However, up to our knowledge, an analysis about the kinetics parameters that are controlling the cobalt electrodeposition onto SSE from ammoniacal solutions has not been analyzed yet. Thus, in the present work, we carried out an electrochemical and morphological study, in order to understand the Co electrodeposition process onto this system.

\section{METHODOLOGY}

\section{Experimental}

Cobalt electrodeposits onto stainless steel electrode 304 were carried out from an aqueous solution containing $0.1 \mathrm{M} \mathrm{CoSO}_{4}+1.0 \mathrm{M}\left(\mathrm{NH}_{4}\right)_{2} \mathrm{SO}_{4}$ at $25^{\circ}$ $\mathrm{C}$ and $\mathrm{pH}=4.5$. All solutions were prepared using analytic grade reagents with ultra pure water (Millipore-Q system) and were deoxygenated by bubbling $\mathrm{N}_{2}$ for 15 minutes before each experiment. The working electrode was an SSE-304 disc with $0.91 \mathrm{~cm}^{2}$ of area. The exposed surface was polished to a mirror finish with different grades of alumina down to $0.05 \mathrm{~mm}$ and ultrasonically cleaned before experiments. A graphite bar with an exposed area greater than the working electrode was used as counter electrode. A saturated silver electrode $(\mathrm{Ag} / \mathrm{AgCl})$ was used as the reference electrode, and all measured potentials are referred to this scale. The electrochemical experiments were carried out in a BAS potentiostat connected to a personal computer running the BAS100W software to allow the control of experiments and data acquisition. In order to verify the electrochemical behavior of the electrode in the electrodeposition bath, cyclic voltammetry was performed in the 0.600 to $-1.000 \mathrm{~V}$ potential range. The kinetic mechanism of cobalt deposition onto SSE-304 was studied under potentiostatic conditions by the analysis of the experimental potentiostatic current density transients recorded through the potential step technique. The perturbation of the potential electrode always started at 0.600 $\mathrm{V}$. The first potential step was imposed at different potentials detailed in this work. Microstructures of electrodeposits were examined by using a scanning electron microscope (SEM; JEOL6300) equipped with an energy-dispersive $\mathrm{X}$-ray spectrometer (EDS).

\section{RESULTS AND DISCUSSION}

\section{Voltammetric study}

The electrodeposition technique is valuable because of its cost effectiveness, easy maintenance and quality deposits 9 . However, it needs a good knowledge of the nucleation and growth parameters to get deposits with reproducible properties ${ }^{10}$. Thus, it is important to determine the potentials where the deposit can be obtained. To find out the values where the cobalt electrodeposition starts, we carried out a voltammetric study at different scan rates $(n)$. Figure 1 shows the voltammetric response, with a scan rate of $20 \mathrm{mV}$ $\mathrm{s}^{-1}$, obtained from SS-304/10-1 $\mathrm{M}$ of $\mathrm{CoSO}_{4}+1 \mathrm{M}\left(\mathrm{NH}_{4}\right)_{2} \mathrm{SO}_{4}$ system. Observe at direct scan, the formation of a peak $\mathrm{A}$ at $-0.860 \mathrm{~V}$. During the inverse of the potential scan, it is possible to observe the crossover, $E_{\mathrm{C} 1}(-0.790 \mathrm{~V})$ which is typical of the formation of a new phase involving a nucleation process ${ }^{11}$. Sometimes, the second crossoverpotential $E_{\mathrm{C} 2}(-0.360 \mathrm{~V})$ may be associated to the thermodynamical potential of $\mathrm{M}^{\mathrm{n}+} / \mathrm{M}$, only when $E_{\mathrm{C}}$ is independent of the switch potential $E_{1}$ and when $E_{1}$ is less negative than the corresponding peak potential ${ }^{12}$. However, this was not the case for the $E_{\mathrm{C} 2}$ analyzed in this work. In the anodic zone, it was possible to observe a principal peak $\mathrm{C}$ at around 0.260 $\mathrm{V}$, preceded by a shoulder B $(-0.182 \mathrm{~V})$. Shoulder B has been associated with the dissolution of a hydrogen rich cobalt phase ${ }^{13}$. Also, it is shown the cobalt electrodeposition which starts at $-0.630 \mathrm{~V}\left(E_{\text {crist }}\right)$.

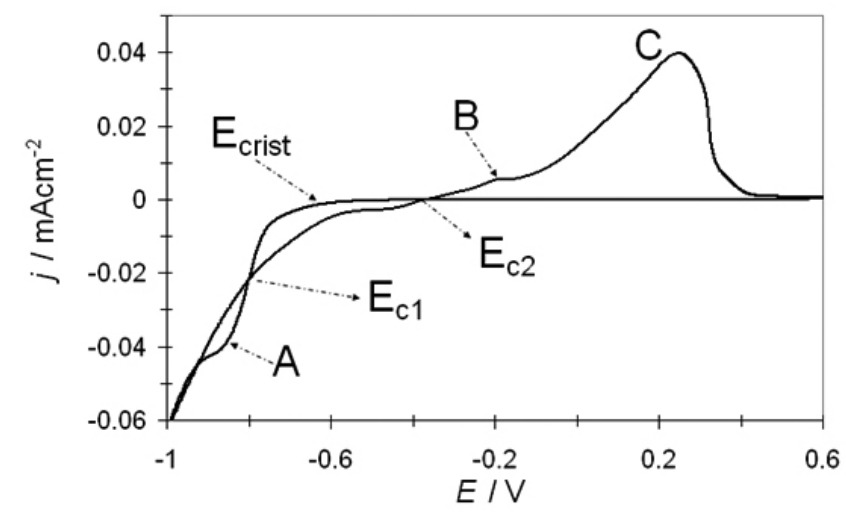

Fig. 1. A cyclic voltammogram obtained from the SSE-304/10-1 $\mathrm{M}$ of $\mathrm{CoSO}+1 \mathrm{M}\left(\mathrm{NH}_{4}\right)_{2} \mathrm{SO}_{4}(\mathrm{pH} 4.5)$ system. The potential scan was started at $0.600 \mathrm{~V}$ toward the negative direction with a potential scan rate of $20 \mathrm{mV} \mathrm{s}^{-1}$.

To determine the limiting control of the cobalt reduction process, the maximum current density $\left(j_{p}\right)$ value associated with peak A was plotted as a function of $n^{1 / 2}$, Figure 2. Note, in this plot, a linear relationship which suggest a diffusion-controlled process according to the Berzins-Delahay's equation ${ }^{14,15}$. 


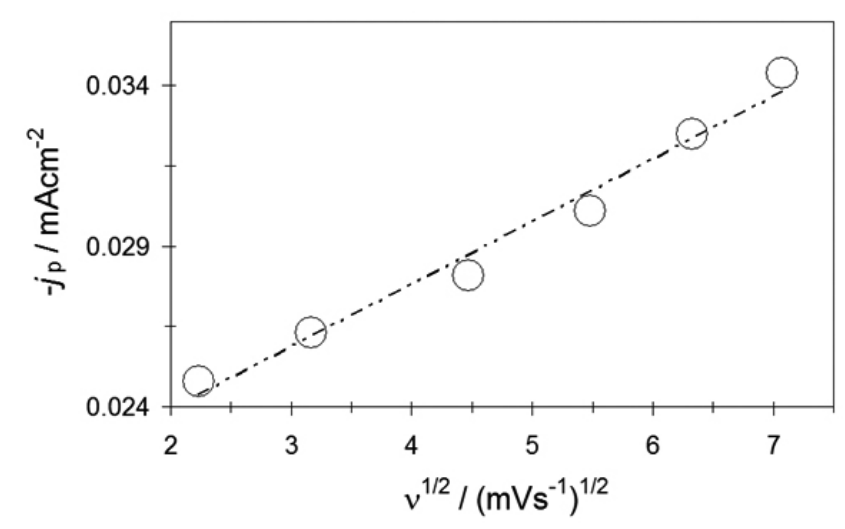

Figure 2. Plot of the experimental cathodic peak current density $\left(j_{\mathrm{p}}\right)$ as a function of scan rate $\left(n^{1 / 2}\right)$. The broken straight line corresponds to the linear fit of the experimental data.

\section{Chronoamperometric study.}

Formation of new phases occurs through nucleation and growth mechanisms and the corresponding current transients can provide valuable information about the kinetics of electrodeposition. Figure 3 shows a set of current density transients recorded at different potentials by the potential step technique. These transients were obtained by applying an initial potential of $0.600 \mathrm{~V}$ on the surface of the SSE-304 electrode. At this potential value, the cobalt deposition had still not begun, see Figure 1. After the application of this initial potential, a step of negative potential $\left(E_{\mathrm{c}}\right)$ was varied on the surface of the electrode for $32 \mathrm{~s}$. All transients showed a typical current maximum $\left(j_{m}\right)$ which is characteristic of a typical three dimensional nucleation process ${ }^{16}$, ${ }^{17} \mathrm{~m}$. The decayed current recorded after the current maximum was analyzed employing the Cottrell's equation ${ }^{18}$. However, Cottrell's equation could not predict the behavior obtained (not shown), suggesting the presence of an additional process to the cobalt electrodeposition process ${ }^{19}$.

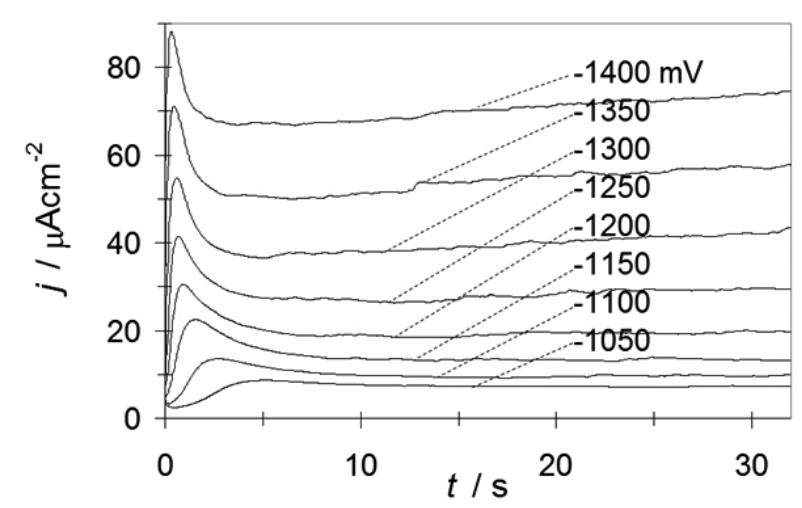

Figure 3. A set of transients obtained from the SSE-304/10-1 $\mathrm{M}$ of CoSO $+1 \mathrm{M}\left(\mathrm{NH}_{4}\right)_{2} \mathrm{SO}_{4}(\mathrm{pH} 4.5)$ system by means of the potential step technique for different potential step values $(\mathrm{mV})$ indicated in the figure. In all the cases the initial potential was $0.600 \mathrm{~V}$

To determine the nucleation and growth mechanism, as progressive or instantaneous, we compared the experimental transients, with their dimensionless curves by following the established by Sharifker et al. ${ }^{16,}{ }^{17}$. These curves were plotted substituting the coordinates of the experimental local maximum $\left(t_{\mathrm{m}}, j_{\mathrm{m}}\right)$, in

$$
\frac{j^{2}}{j_{m}^{2}}=1.9542\left(\frac{t}{t_{m}}\right)^{-1}\left\{1-\exp \left[-1.2564\left(\frac{t}{t_{m}}\right)\right]\right\}^{2}
$$

for instantaneous nucleation and in

$$
\frac{j^{2}}{j_{m}^{2}}=1.2254\left(\frac{t}{t_{m}}\right)^{-1}\left\{1-\exp \left[-2.3367\left(\frac{t}{t_{m}}\right)^{2}\right]\right\}^{2}
$$

for progressive nucleation. Figure 4 shows a comparison of the theoretical dimensionless transients, generated by equations (1) and (2) with an experimental dimensionless current transient reported in Figure 3. Observe that at $\left(t / t_{\mathrm{m}}<1\right)$, it was not possible to classify the nucleation as instantaneous or progressive. Here, it must be reminded that the theoretical curves generated by equations (1) and (2) correspond to two extreme cases of the nucleation process and in some cases a classification it is not possible ${ }^{20}$. At $\left(t / t_{\mathrm{m}}>1\right)$ there is a deviation from the predicted by equation (1) and (2). This behavior may be indicative of the presence of other contributions to the overall current during the Co deposition process additional to the $3 \mathrm{D}$ nucleation contribution ${ }^{19}$.

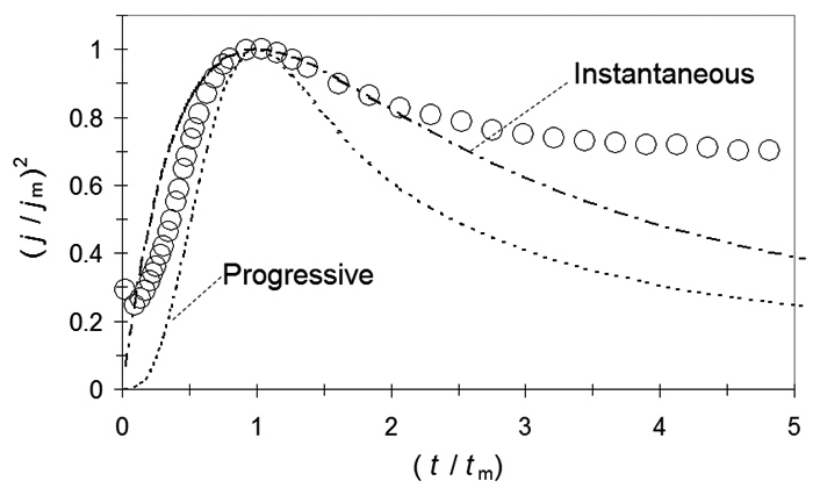

Figure 4. Comparison of a non-dimensional experimental transient with the theoretical non-dimensional curves generated by (Eq. (1)) and (Eq. (2)).

\section{Analysis of the transients}

Shoulder B, observed in Figure 1, indicates that the proton reduction process is present due to the existence of a hydrogen rich Co phase ${ }^{13}$. It has been proposed that when the proton reduction occurs simultaneously with the growth of Co centers under a diffusion-controlled process, the overall current density is given by ${ }^{21}$ :

$$
\begin{aligned}
& j(t)=\left(P_{1}^{*}+P_{4} t^{-1 / 2}\right) \times\left(1-\exp \left\{-P_{2}\left[t-\frac{1-\exp \left(-P_{3} t\right)}{P_{3}}\right]\right\}\right) \\
& \text { where } \\
& P_{1}=z_{P R} F k_{P R} \\
& P_{1}^{*}=P_{1}\left(\frac{2 c_{0} M}{\pi \rho}\right)^{1 / 2} \\
& P_{2}=N_{0} \pi k D \\
& P_{3}=A \\
& P_{4}=\frac{2 F D^{1 / 2} c_{0}}{\pi^{1 / 2}} \\
& k_{P R}=k_{P R}^{0} \exp \left(-\frac{\alpha_{P R} z F E}{R T}\right)
\end{aligned}
$$

where $z_{P R} F$ is the molar charge transferred during the proton reduction process, $k_{P R}$ is the rate constant of the proton reduction reaction, $k=\left(8 \pi c_{0} / \rho\right)^{1 / 2}$ ,$N_{0}$ is the number of active nucleation sites, $A$ is the nucleation rate, $D$ is the coefficient diffusion, $E$ is the potential applied, $F$ is the Faraday's constant and all others parameters have their conventional meanings. Figure 5 shows a comparison of a reduction experimental current transient, with one theoretically 
generated by non-linear fitting of experimental data to Eq. (3). It can be observed, that the model expressed by this equation adequately accounted for the behavior of the experimental transient. The physical parameters obtained from the adjustments of Eq. (3) are reported in Table 1. The average diffusion coefficient calculated from the fittings was $9.8 \times 10^{-6} \mathrm{~cm}^{2} \mathrm{~s}^{-1}$. On the other hand, it is seen (Table 1) that an increment of the $k_{\mathrm{PR}}, A$ and $N_{0}$ is obtained when the potential applied is decreased. An increase in $k_{\mathrm{PR}}$ values indicates that the reduction proton process is favored, suggesting a competition for the active sites on the surface by the $\mathrm{H}^{+}$ions with the $\mathrm{Co}^{2+}$ cations.

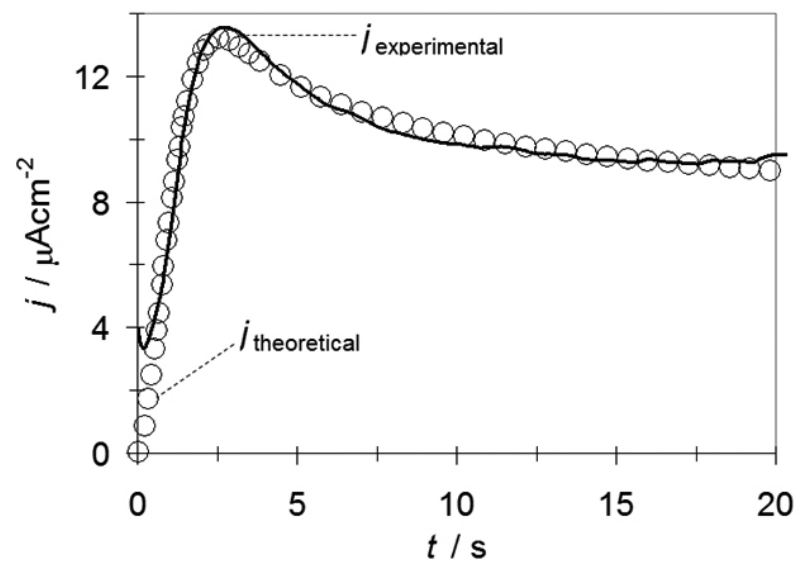

Figure 5. Comparison between an experimental current transient (-) recorded at $-1100 \mathrm{mV}$ with the theoretical transient $(\mathrm{O} O \mathrm{O})$ generated by nonlinear fitting of Eq. (3) to the experimental data.

Table 1. Potential dependence of the nucleation parameters during Co electrodeposition onto an SSE-304 electrode from aqueous solution containing $10^{-1} \mathrm{M}$ of $\mathrm{CoSO}_{4}+1 \mathrm{M}\left(\mathrm{NH}_{4}\right)_{2} \mathrm{SO}_{4}$. at $\mathrm{pH} 4.5$. The values were obtained from best-fit parameters found through the fitting process of the experimental $j$ - $t$ plots by using Eq. (3).

\begin{tabular}{|ccccc|}
\hline $\begin{array}{c}E \\
/ \mathrm{mV}\end{array}$ & $\begin{array}{c}k_{\mathrm{PR}} \mathrm{X} 10^{-7} \\
/ \mathrm{mol} \mathrm{cm}^{-2} \mathrm{~s}^{-1}\end{array}$ & $\begin{array}{c}A \\
/ \mathrm{s}^{-1}\end{array}$ & $\begin{array}{c}D X 10^{5} \\
/ \mathrm{cm}^{2} \mathrm{~s}^{-1}\end{array}$ & $\begin{array}{c}N_{0} \mathrm{X} 10^{-6} \\
/ \mathrm{cm}^{2}\end{array}$ \\
\hline 1050 & 0.532 & 0.145 & 0.785 & 0.18 \\
\hline 1100 & 0.649 & 0.245 & 1.122 & 0.86 \\
\hline 1150 & 0.894 & 1.223 & 1.576 & 0.73 \\
\hline 1200 & 1.517 & 3.526 & 1.354 & 1.00 \\
\hline 1250 & 2.400 & 7.537 & 1.222 & 1.38 \\
\hline 1300 & 3.617 & 33.808 & 1.008 & 1.63 \\
\hline 1350 & 5.491 & 102.514 & 0.404 & 3.43 \\
\hline 1400 & 7.193 & 235.097 & 0.354 & 5.24 \\
\hline
\end{tabular}

Analysis of the kinetic parameters.

From the nucleation rate values reported in Table 1, it is possible to calculate the Gibbs free energy of nucleation employing the next equation ${ }^{22-24}$ :

$$
A=k_{3} \exp \left(-\frac{\Delta G}{K_{B} T}\right)=k_{3} \exp \left(-\frac{k_{4}}{\eta^{2}}\right)
$$

where $\Delta G$ is the Gibbs free energy of nucleation, $\mathrm{J} /$ nuclei; $K_{B}$ is the Boltzmann constant $\left(1.38066 \times 10^{-23} \mathrm{~J} \mathrm{~mol}^{-1}\right), k_{2}=N_{0} \omega \Gamma$ where, $\omega_{n_{\mathrm{H}}}$ is the frequency of attachment of single atoms to the critical nucleus and $\Gamma$ is the non-equilibrium Zeldovich factor which depends exponentially on the overpotential ${ }^{25}$. On the other hand, $k_{4}=-\left(6 \pi{ }^{3} M^{2} \phi(\theta) / 3 \rho^{2} z^{2} F^{2} \pi\right)$, where $\gamma$ is the interfacial tension of nucleus with its motherphase, $\phi(\theta)$ is a function of the contact angle $\theta$ between the nucleus and the substrate ${ }^{25}$. In order to calculate the value of Gibbs free energy of nucleation from experimental transients, an $\ln$ $A$ vs. $\eta^{-2}$ plot can be constructed according to Eq. (10), and then from the slope $k_{4}$ of the observed linear relationship, $\Delta G$ could be calculated at each particular overpotential by using the next equation:

$$
\left(-\frac{\Delta G}{K_{B} T}\right)=\frac{k_{5}}{\eta^{2}}
$$

where $T$ is the absolute temperature, $\mathrm{K}$. The plot $\ln A v s \eta^{-2}$ plot, showed a linear relationship giving a slope of -3.6 ; the average $\Delta G$ calculated at different potentials was $1.013 \times 10^{-20} \mathrm{~J} /$ nuclei. This energy corresponds to the $\Delta G$ value requirements for the formation of stable nucleus ${ }^{23,24}$. The $\Delta G$ value obtained is slightly bigger than the value obtained for the electrocrystallization of Co on GCE and HOPG from sodium and ammonia sulfate solutions ${ }^{26,27}$.

In the framework of the atomistic theory of electrolytic nucleation, it is possible to estimate the critical size of the Co nucleus $\left(n_{c}\right)$ from the potential dependence of $A$ through the following equation ${ }^{28}$ :

$$
n_{c}=\left(\frac{k_{B} T}{z e_{0}}\right)\left(\frac{d \ln A}{d \eta}\right)-\alpha_{C o}
$$

where $\alpha_{6}$ is the transfer coefficient for Co reduction. The plot $\ln A$ vs $E$ showed a linear tendency with a $\mathrm{d}(\ln A) / \mathrm{d}(h)=22.05$. Thus, the critical cluster's size calculated employing eq(12) and $\alpha_{6}=0.5$ was $n_{c}=0$. This value suggests that each active site is a critical nucleus on the SSE-304 surface. Similar results have been obtained for the Co electrodeposition from sodium and ammonia sulfate solutions onto GCE and HOPG electrode ${ }^{24,25}$.

\section{Morphological analysis}

Figure 6 shows the SEM micrographs of cobalt deposits when a potential of $-1350 \mathrm{mV}$ was applied onto the SSE-304 surface during $192 \mathrm{~s}$. From this figure it can be observed granular deposits, Figure 6a. An increase in magnification, Figure $6 \mathrm{~b}-\mathrm{c}$, indicated the existence of non-uniform particles. It is interesting to note that the non-uniformity of the cobalt deposited may be related either the morphology of the metallic substrate or the hydrogen evolution. Also, it is important to consider that the potential of hydrogen evolution is very close to the cobalt electrodeposition potential causing a competition between both processes ${ }^{29}$. Additionally, the random formation of hydrogen bubbles on the electrode may cause a non uniform area available on SSE causing the formation of a non uniform deposit of cobalt. The EDS analysis of the particles shown in Figure 7 indicated that the chemical composition is cobalt. a)

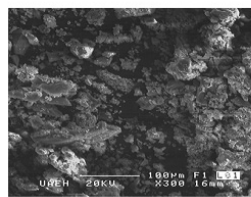

b)

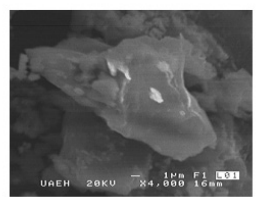

c)

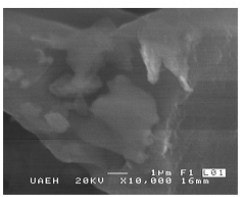

Figure 6. SEM images of Co electrodeposited under potentiostatic conditions at $-1350 \mathrm{mV}$ from SSE- $304 / 10^{-1} \mathrm{M}$ of $\mathrm{CoSO}_{4}+1 \mathrm{M}\left(\mathrm{NH}_{4}\right)_{2} \mathrm{SO}_{4}(\mathrm{pH}$ 4.5). a) $300 \mathrm{X}$, b) $4000 \mathrm{X}$ and c) $10000 \mathrm{X}$.

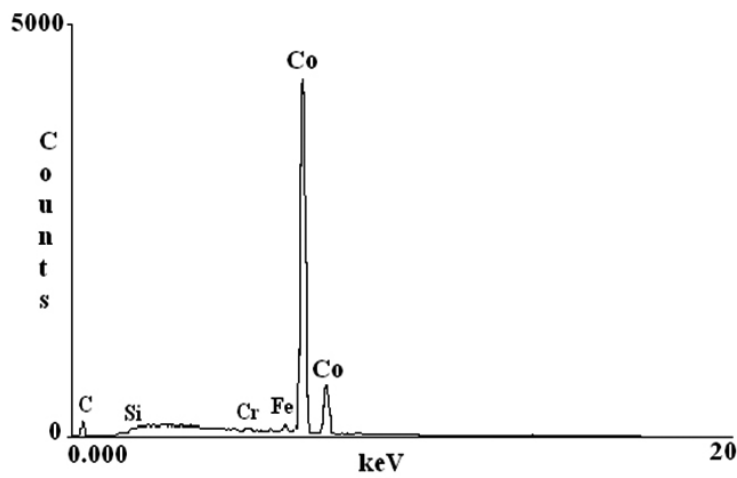

Figure 7. EDS spectrum of the cobalt deposits showed in Figure 6. 


\section{CONCLUSIONS}

We have studied the Co electrodeposition onto Stainless Steel electrode 304 from $10^{-1} \mathrm{M} \mathrm{CoSO}_{4}, 1 \mathrm{M}\left(\mathrm{NH}_{4}\right)_{2} \mathrm{SO}_{4}$ aqueous solution by using the cyclic voltammetric and potentiostatic techniques. Black cobalt deposits were obtained in our experimental conditions. Nucleation parameters such as nucleation rate, density of active nucleation sites and saturation nucleus were determined from potentiostatic studies. An increase in $k_{\mathrm{pP}}, A$ and $N_{0}$ was obtained when the potential applied was decreased. The morphological analysis indicated the formation non-uniform particles with grain agglomeration.

\section{ACKNOWLEDGMENTS}

N.R.L. is grateful for a graduate student fellowship from CONACYT. This work was done in partial fulfillment of N.R.L.'s Ph.D. requirements. We gratefully acknowledge financial support from CONACyT project APOYCOMPL-2008 No. 91261 and to the Universidad Autónoma del Estado de Hidalgo. Authors acknowledge Juan Hernández Ávila for the SEM technical assistance.

\section{REFERENCES}

1. X. Deng, P. Wei, M. R. Bateni, and A. Petric. J. Power Sources 160, 1225 (2006).

2. R. N. Thokale, P. S. Patil and M. B. Dongare. Mater. Chem. Phys. 74, 143 (2002).

3. E. Barrera. M. Palomar-pardave, N. Batina, I. Gonzalez. J. Electrochem. Soc. 147, 1787 (2000).

4. B. Tutunaru, A. Patru,. M. Preda. Rev. Chim. 57, 598 (2006).

5. M. Dinamani, P.V.Kamath. J. Appl. Electrochem. 30, 1157 (2000).

6. R.González-Ramírez, H. Jiménez-Domínguez, O. Solorza-Feria, E. Ordóñez-Regil, A. Cabral-Prieto and S. BulbulianJ. Radioanal. Nucl. Chem. J. Radioanal. Nucl. Chem. 174, 291 (1993).

7. M. Ohba, Z. Panossian and P. Camargo. Trans. Inst. Met. Finish. 83, 199 (2005).

8. M. Rivera, C.H. Rios-Reyes, L.H. Mendoza-Huizar. Appl. Surf. Sci. 255, 1754 (2008).
9. R.N. Emersow, J. Chil. Chem. Soc., 52, 1322-1325 (2007).

10. L.H. Mendoza-Huizar, C.H. Rios-Reyes. J Solid State Electrochem., 15, 737-745, 2011.

11. R. Greef, R. Peat, L.M. Peter, D. Pletcher, J. Robinson. Instrumental Methods in Electrochemistry. Ellis Horwood, Chichester, 1985.

12. A. Rojas-Hernández, T.M. Ramírez, J.G. Ibáñez, I. González. J. Electrochem. Soc. 138, 365 (1991).

13. M. Palomar-Pardave, I. Gonzalez, A.B. Soto, E.M. Arce. J Electroanal Chem 443, 125 (1998).

14. T. Berzins, P. Delahay. J. Am. Chem. Soc. 75, 555 (1953).

15. P. Delahay. New Instrumental Methods in Electrochemistry, Interscience, New York, 1954.

16. B.R. Scharifker, G. Hills. Electrochim Acta 28, 879 (1983).

17. B.R. Scharifker, J. Mostany. J. Electroanal Chem 177, 13 (1984).

18. A.J. Bard, L.R. Faulkner Electrochemical Methods. Fundamental and Applications. Wiley, New York, 2001.

19. L.H. Mendoza-Huizar, J. Robles, M. Palomar-Pardave. J Electroanal. Chem. 545, 39 (2003).

20. L. Heerman, A. Tarallo. Electrochem Commun. 2,85 (2000).

21. M. Palomar-Pardavé, B.R. Scharifker, E.M. Arce, M. Romero-Romo. Electrochim. Acta. 50, 4736 (2005).

22. Southampton Electrochemistry Group, Instrumental Methods in Electrochemistry, Wiley, New York, 1985.

23. J. Mostany, J. Mozota, B.R. Scharifker. J. Electroanal. Chem., 177, 25 (1984).

24. A. Serruya, J. Mostany, B.R. Scharifker. J. Electroanal. Chem., 464, 39 (1999).

25. A. Milchev, Electrocrystallization: Fundamentals of nucleation and growth, Kluwer Academic Publishers, 2002, Chapter 2.2.3).

26. C.H. Rios-Reyes, L.H. Mendoza-Huizar, M. Rivera. J Solid State Electrochem., 14, 659-668, (2010)

27. C.H. Rios-Reyes, M. Granados-Neri, L.H. Mendoza-Huizar. Quim. Nova, 32, 2382-2386, (2009)

28. A. Milchev. Contemporary Physics 32, 321 (1991).

29. Z. L. Bao, K. L. Kavanaugh, J. Cryst. Growth, 287, 514-517 (2006). 